\title{
RELAÇÃO DO CONSUMO DE VITAMINAS E MINERAIS COM O SISTEMA IMUNITÁRIO: UMA BREVE REVISÃO
}

\author{
RELATION OF VITAMIN AND MINERAL CONSUMPTION WITH THE IMMUNE \\ SYSTEM: A BRIEF REVIEW
}

\section{Mayara do Belem Caldas BIASEBETTI', Isis Delfrate RODRIGUES'1, Caryna Eurich MAZUR $^{2}$}

1 - Nutricionista - Universidade Estadual do Centro-Oeste - UNICENTRO. Guarapuava, Paraná, Brasil. 2 - Nutricionista. Mestre em Segurança Alimentar e Nutricional. Departamento de Nutrição/UNICENTRO, Guarapuava, Paraná, Brasil.

Autor para correspondência: mayara.biasebetti@hotmail.com

\section{RESUMO:}

O sistema imunitário é o sistema de defesa do corpo humano, e é constituído por uma complexa rede de células e moléculas dispersas por todo o organismo. Este sistema tem importante relação com a nutrição pois há interação entre a ingestão adequada de nutrientes, o aumento no estresse oxidativo e a ocorrência de processos infecciosos, com depleção imunitária. Esse artigo trata-se de revisão de literatura colocando em destaque os principais nutrientes que agem em benefício do sistema imunitário: ferro, vitamina $A$, vitamina $C$, vitamina $E$, vitamina $D$ e zinco, e destaca sua relação com o sistema imunitário. Palavras-chaves: Sistema imunológico. Nutrição. Alimentação. Imunidade. Nutrientes.

\section{ABSTRACT:}

The immune system is a defense system of the body, it a complex of cells and molecules dispersed in the body. This relationship with nutrition in the issue of interaction between adequate intake of nutrients, increase in oxidative stress and the occurrence of infectious processes and immune depletion. This article it is literature review by highlighting the key nutrients that act on behalf of the immune system: iron, vitamin $A$, vitamin $C$, vitamin $E$, vitamin $D$ and zinc, and highlights its relationship to the immune system. Keywords: Immune system. Nutrition. Feeding. Immunity. Nutrients.

\section{INTRODUÇÃO}

O sistema imunitário é o sistema de defesa do corpo humano que atua contra microorganismos que agem em inúmeras substâncias estranhas presentes no ar, nos alimentos ou nos objetos, sendo essencial contra o desenvolvimento de infecções e tumores. É constituído por uma complexa rede de células e moléculas dispersas por todo o organismo, se caracterizando biologicamente pela habilidade de reconhecer especificamente algumas composições moleculares ou antígenos e desenvolver uma resposta efetiva diante destes estímulos, provocando a sua destruição ou inativação (PRIETO, SANZ, ALVAREZ-MON, 
1997; BRODIN et al., 2015).

As pesquisas que buscavam a relação entre imunidade e nutrição surgiram em meados da década de 70 quando testes imunológicos foram implantados como componentes da avaliação do estado nutricional (KATONA, KATONA-APTE, 2008). Outra questão importante é a interação entre a ingestão adequada de nutrientes, o aumento no estresse oxidativo e a ocorrência de processos infecciosos, com depleção imunitária. (LEITE, SARNI, 2003).

As principais células de defesa do sistema imunitário são uma classe de glóbulos brancos móveis, os leucócitos. Existem dois tipos distintos de leucócitos: fagócitos, que englobam os macrófagos, neutrófilos e células dendríticas; e os linfócitos, que englobam as células B, células T e células exterminadoras naturais (GREDEL, 2012).

Ainda, são vários os fatores capazes de modificar o comportamento do sistema imunitário, como a idade, os fatores genéticos, metabólicos, ambientais, anatômicos, fisiológicos, nutricionais e microbiológicos (PEREIRA, DAS GRAÇAS CARDOSO, 2012).

Estudos têm mostrado que uma alimentação regrada juntamente com nutrientes específicos beneficia a resposta imunológica quando associados também ao exercício físico (DE ARAUJO et al., 2014; VELDHOEN, FERREIRA, 2015).

O presente artigo, buscou fazer uma revisão de literatura colocando em destaque os principais micronutrientes que agem em benefício do sistema imunitário.

\section{METODOLOGIA}

Para isso alcançar o objetivo do estudo, foram buscados artigos nas bases de dados Scielo e CAPES que englobavam o período de 2000 a 2015 . Assim, inicialmente foi efetivada uma busca sobre a imunidade e nutrientes. Foi, ainda, realizado o agrupamento das palavras-chave da seguinte forma: "imunidade e alimentação", "imunidade e nutrição", "sistema imunológico e nutrientes". Os critérios utilizados para a seleção da amostra foram: artigos que abordassem a temática da imunidade, dentro de todas as áreas de interesse da nutrição. Deste modo, foram encontrados mais de 200 artigos referentes. Ao final, foram selecionados 14 artigos, sendo organizados em pastas nas quais constavam dados de identificação dos artigos, conforme os nutrientes abaixo citados.

\section{RESULTADOS}

\subsection{Ferro}

O ferro faz parte da composição de várias proteínas, incluindo enzimas, mioglobina 
e hemoglobina. As principais fontes deste mineral são as carnes, principalmente as vermelhas e vísceras, pois possuem maior quantidade de ferro heme. O leite humano (LH) é composto por 0,5 mg/litro, em média, de ferro, com elevada biodisponibilidade. Vários estudos têm associado a deficiência de ferro a defeitos tanto na resposta imunitária adaptativa quanto na resposta inata do indivíduo (PINTO, 2006; CHERAYIL, 2011).

Dentre estes defeitos estão a diminuição na proliferação e no número de células $T$, juntamente com a diminuição de citocinas, relacionados com resposta imunitária adaptativa, e também a diminuição da capacidade fagocitária dos neutrófilos sendo relacionada com os defeitos na resposta inata (SARNI, 2010; CASSAT E SKAAR, 2013).

\subsection{Zinco}

O zinco é um micronutriente encontrado principalmente em carnes, laticínios, frutos do mar e cereais. As funções biológicas do zinco podem ser divididas em catalíticas, estruturais e regulatórias. Esse nutriente é também essencial para a estrutura de algumas proteínas envolvidas na expressão gênica tendo influencia na apoptose e na atividade da proteína $\mathrm{C}$ quinase. Em relação a função estrutural, ele participa como parte integrante de enzimas antioxidantes como a cobre-zinco-superóxido dismutase (DOMENE et al., 2008; SARNI, 2010).

A relação existente entre o zinco e as células do sistema imunitário é com atividade de células $T$ auxiliadoras, desenvolvimento de linfócitos $T$ citotóxicos, retardamento da hipersensibilidade, proliferação de linfócitos T, produção de interleucina-2 e apoptose de células de linhagens mielóide e linfóide. Na deficiência de zinco observa-se a redução na produção de citocinas (MACDONALD, 2000; ROSENKRANZ et al., 2015). Sendo assim, o zinco é um micronutriente essencial para o crescimento, desenvolvimento e função imunológica.

\subsection{Vitamina A}

A vitamina A é encontrada em fontes dietéticas de origem animal, como fígado, peixe, leite e derivados. E os óleos, frutas e vegetais possuem carotenóides, que são convertidos em vitamina A no organismo (WEST, 2002; SOUZA et al., 2002; BROWN, NOELLE, 2015).

Desempenha papel na resposta de células fagocitárias, estimulando a fagocitose, 
a ativação da citotoxicidade mediada por células e o aumento na resposta de timócitos a mitógenos específicos (GREDEL, 2012). O ácido retinoico proporciona liberação seletiva de interleucina-1 por monócitos do sangue periférico de seres humanos, também aumenta a porcentagem de células linfóides que expressam marcadores de superfície de linfócitos T auxiliares, já o o $\beta$-caroteno aumenta a porcentagem de células linfóides com expressão de marcadores de células natural-killers, o que implica uma atuação diferente dos vários retinóides na imunidade celular específica (SOUZA et al., 2002; GREDEL, 2012).

\subsection{Vitamina D}

A vitamina $\mathrm{D}$ pode ser encontrada em alimentos como óleo de peixe, óleo de fígado de bacalhau e gema de ovo, porém sua ação depende da síntese na pele pela exposição solar (GREDEL, 2012).

Esta vitamina desempenha várias funções, como no metabolismo do cálcio e formação óssea. A vitamina $D$ desempenha interação com o sistema imunológico além da sua função no metabolismo do cálcio e formação óssea (JONES, TWOMEY, 2008; ARNSON, AMITAL, SHOENFELD, 2007).

A sua ação através da diferenciação e regulação dos linfócitos, macrófagos e células natural killer, também interfere na produção de citocinas in vivo e in vitro. Possui efeitos imunomoduladores, diminuindo a produção de interleucina-2, do interferongama e do fator de necrose tumoral; inibição da expressão de interleucina-6 e inibição da secreção e produção de auto anticorpos pelos linfócitos B (LEMIRE, TAKASHIMA, 1992; LINKERISRAELI et al., 2001; DE ROSA et al., 2015).

\subsection{Vitamina $\mathbf{E}$}

A vitamina $E$ é encontrada em grande variedade de alimentos de origem vegetal, como: óleos vegetais, germe de trigo, milho e soja. A deficiência desta vitamina pode comprometer vários aspectos da resposta imune, entre eles a imunidade mediada por células $B$ e $T$. A vitamina $E$ quando suplementada em concentração muito acima da recomendada contribui positivamente para alguns aspectos da função imunitária, por exemplo pode contribuir para a melhora da resposta imunitária celular e diminuição da produção da prostaglandina E2 nos idosos (BATISTA, COSTA e PINHEIRO-SANT'ANA, 2007; GREDEL, 2012). 


\subsection{Vitamina C}

A vitamina C é encontrada principalmente em frutas e hortaliças. Esta é encontrada em grande concentração nas células imunes, porém na presença de infecções e, distúrbios que aumentam o nível de estresse, essa concentração pode diminuir rapidamente. Possui atividade antioxidante, a qual evita o dano oxidativo das células imunes. Ela também auxilia nas funções dos fagócitos, a produção de citocinas, a proliferação de linfócitos $T$ e a expressão gênica das moléculas de adesão dos monócitos (MAHAN, ARLIN, 2002; GREDEL, 2012; SORICE et al., 2014).

\section{CONCLUSÃO}

Foi observado que o ferro, vitamina $\mathrm{C}$ e zinco auxiliam o sistema imunitário na proliferação das células $T$. A vitamina $A$ e $D$ são correlacionadas à mediadores de interleucina 1 e 2.

A partir disso, conclui-se que a relação do sistema imunitário e a nutrição está em uma ingestão adequada de alimentos com nutrientes específicos, como as vitaminas e minerais supracitados, favorecendo diretamente nas funções das células de defesa do organismo e melhorando a qualidade de vida dos indivíduos.

\section{REFERÊNCIAS}

ARNSON, Y.; AMITAL, H.; SHOENFELD, Y. Vitamin D and autoimmunity: new aetiological and therapeutic considerations. Annals of the rheumatic diseases, v. 66, n. 9, p. 1137-1142, 2007.

BATISTA, E. S; COSTA, A. V.; PINHEIRO-SANT'ANA, H.M. Adding vitamin E to foods: implications for the foods and for human health. Revista de Nutrição, v. 20, n. 5, p. 525-535, 2007.

BRODIN, P.; JOJIC, V.; GAO, T. et al. Variation in the Human Immune System Is Largely Driven by Non-Heritable Influences. The Cell, v.160, n.1-2, p.37-47, 2015.

BROWN, C.C.; NOELLE, R.J. Seeing through the dark: New insights into the immune regulatory functions of vitamin A. European Journal Immunology, v.45, n.5, p.1287-95, 2015. 
CASSAT, J.E.; SKAAR, E.P. Iron in Infection and Immunity. Cell Host \& Microbe, v.13, n.5, p.509-19, 2013.

CHERAYIL, B.J. The role of iron in the immune response to bacterial infection. Immunologic Research, v.50, n.1, p. 1-9, 2011.

DE ARAÚJO, A. P. S; GOUVÊA, J. A. G; MARTINS, J. Influência da prática de exercícios físicos sobre os padrões morfofuncionais, função imunológica e qualidade de vida de idosos com aids: estudo de casos. MTP\&Rehabilation Journal, v.12, p.146-172, 2014.

DE ROSA, V.; GALGANI, M.; SANTOPAOLO, M. et al. Nutritional control of immunity: Balancing the metabolic requirements with an appropriate immune function. Seminars in Immunology, v.27, n.5, p.300-9, 2015.

DOMENE, S.M.A.; PEREIRA, T.C.; ARRIVILLAGA, R.K. Estimated zinc availability in school meals done with standard foods in the city of Campinas (SP), Brazil. Revista de Nutrição, v. 21, n. 2, p. 161-167, 2008.

GREDEL, S. Nutrição e imunidade no homem. 2. ed. Bélgica: Ilsi Europe Concise Monograph Series, 2012. 32 p.

JONES, B. J.; TWOMEY, P. J. Issues with vitamin D in routine clinical practice. Rheumatology, v. 47, n. 9, p. 1267-1268, 2008.

KATONA, P.; KATONA-APTE, J. The Interaction between Nutrition and Infection. Clinical Infectious Diseases, v. 46, n. 10, p. 1582-1588, 2008.

LEITE, H.P.; SARNI, R.S. Radicais livres, antioxidantes e nutrição. Revista Brasileira de Nutrição Clínica, v. 18, n. 2, p. 87-94, 2003.

LEMIRE, J.M.; INCE, A; TAKASHIMA, M. 1, 25-Dihydroxyvitamin D3 attenuates of expression of experimental murine lupus of MRL/1 Mice. Autoimmunity, v. 12, n. 2, p. 143$148,1992$. 
MACDONALD, R. S. The Role of Zinc in Growth and Cell Proliferation. The Journal of Nutrition, v. 130, n. 5, p. 1500S-1508S, 2000.

MAHAN, K.L.; ARLIN, T.M. Vitaminas. In: Krause, M.V. Alimentos, nutrição e dietoterapia. 10.ed. São Paulo: Roca, 2002. cap.6, p.71103.

PEREIRA, R. J; DAS GRAÇAS CARDOSO, M. Metabólitos secundários vegetais e benefícios antioxidantes. Journal of biotechnology and biodiversity, v. 3, n. 4, 2012.

PINTO, G. M. Deficiência de ferro: resistência ou suscetibilidade a infecções. Revista Médica de Minas Gerais, v. 18, n. 3, p. 191-196, 2008.

PRIETO, A., REYES, E., SANZ, E., ALVAREZ-MON, M. Activación de las subpoblaciones de linfocitos a sus funciones efectoras. Medicine, v.51, p. 2263-7, 1997.

ROSENKRANZ, E.; HILGERS, R.D.; UCIECHOWSKI, P. et al. Zinc enhances the number of regulatory $T$ cells in allergen-stimulated cells from atopic subjects. European Journal of Nutrition, pp.1-11, 2015.

SARNI, R. O. S.; SOUZA, S.I.S.; COCCO, R. et al. Micronutrientes e sistema imunológico. Revista Brasileira de Alergia e Imunopatologia, v. 33, n. 1, p. 8-13, 2010.

SORICE, A.; GUERRIERO E.; CAPONE F. et al. Ascorbic acid: its role in immune system and chronic inflammation diseases. Mini-Reviews in Medicinal Chemistry, v.14, n.5, p.44452, 2014.

SOUZA, W. A; BOAS, V.; DA COSTA, O. M. G. Vitamin A deficiency in Brazil: an overview. Revista Panamericana de Salud Pública, v. 12, n. 3, p. 173-179, 2002.

VELDHOEN, M.; FERREIRA,C. Influence of nutrient-derived metabolites on lymphocyte immunity. Nature Medicine, v.21, n.7, p.709-18, 2015.

WEST, K. P. Extent of vitamin A deficiency among preschool children and women of reproductive age. The Journal of Nutrition, v. 132, n. 9, p. 2857S-2866S, 2002. 